\title{
Nem samba nem futebol: jovens brasileiros gostam mesmo é de ciência e tecnologia
}

\section{Neither samba nor football: what young Brazilians really like is science and technology}

\author{
Pedro Luszi \\ i Pesquisador, Rede Clima, Sub-rede Desenvolvimento Regional - Brasília. \\ Brasília - DF - Brasil \\ orcid.org/0000-0002-1589-8031 \\ luszdobrasil@gmail.com
}

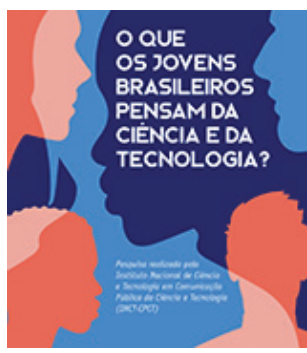

MASSARANI, Luisa et al. (coord.). O que os jovens brasileiros pensam da ciência e da tecnologia? Rio de Janeiro: Fiocruz/ COC, 2021. 115p.
As mudanças climáticas, suas origens e seus impactos estão entre os temas mais estudados das últimas décadas. Existe um significativo nível de concordância entre diferentes correntes de pesquisas científicas sobre o tema (Bastin et al., 2019). A comunicação dos resultados dessas pesquisas amplia a importância do desenvolvimento científico e tecnológico e fortalece o nível de percepção da sociedade sobre esse fenômeno. Estudos mostram que os jovens tendem a um maior engajamento nesse contexto quando conhecem a dimensão dos impactos dessas mudanças, contudo, com raras exceções, são excluídos das discussões sobre a dimensão desse problema que os desafiará em breve (Lee et al., 22 fev. 2020). E no contexto nacional, o que pensam os jovens sobre mudanças climáticas? Sobre pesquisas científicas? Sobre tecnologia? Esta resenha trata de uma produção muito importante que responde a essas e outras incertezas sobre os jovens brasileiros.

Uma equipe de pesquisadoras e pesquisadores brasileiros aceitou o seguinte desafio: perguntar, escutar, organizar e apresentar à sociedade as percepções dos jovens brasileiros sobre ciência e tecnologia (CT). O trabalho culminou com a publicação do livro apresentado nesta resenha, O que os jovens brasileiros pensam da ciência e da tecnologia? (Massarani et al., 2021). A obra é resultado de uma pesquisa realizada pelo Instituto Nacional de Ciência e Tecnologia em Comunicação Pública da Ciência e Tecnologia que foi coordenada por Luisa Massarani (Fundação Oswaldo Cruz); Yurij Castelfranchi (Universidade Federal de Minas Gerais); Vanessa Fagundes (Fundação de Amparo à Pesquisa do Estado de Minas Gerais e Universidade Federal de Minas Gerais); Ildeu Moreira (Universidade Federal do Rio de Janeiro). Trata-se de uma equipe de pesquisadores com ampla experiência em estudos de CT e divulgação científica, com atuação robusta e consistente no cenário nacional e forte 
contribuição em torno da compreensão pública do tema abordado. Os capitais científico, socioeducacional e sociocultural dos autores já asseguram ao livro um lugar de destaque e contribuições fundamentais nos debates sobre produção científica no campo da educação, com a inclusão dos jovens brasileiros nesses debates. A obra tem distribuição gratuita e está disponível em: https://www.inct-cpct.ufpa.br/wp-content/uploads/2021/02/LIVRO_ final_web_2pag.pdf.

O que os jovens brasileiros pensam da ciência e da tecnologia? está organizado em cinco capítulos: "Introdução", "Síntese dos resultados", "Metodologia da pesquisa", "Resultados", "Algumas considerações finais e caminhos possíveis", além de referências e dois anexos. Essa é uma pesquisa longitudinal, inédita no país a respeito das percepções da sociedade, dos jovens em especial, sobre CT. Um survey, como recurso metodológico, foi realizado com 2.206 jovens entre 15 e 24 anos de idade, com diferentes níveis de escolaridade, inseridos em diversos contextos geográficos, socioculturais e socioeconômicos. As coletas de dados foram realizadas nos meses de março e abril de 2019, em todas as regiões do país, alcançando 79 cidades. A equipe que coordenou a pesquisa foi além dos questionamentos básicos para o problema proposto e incluiu no survey temas controversos na sociedade brasileira como mudanças climáticas, vacinação, teoria da evolução e fake news, ampliando, assim, a importância da obra ao priorizar as percepções dos jovens brasileiros no arcabouço das diversidades possíveis nos campos em que a CT se faz presente de forma inclusiva, como defendido no estudo.

Os dados da pesquisa que o livro nos apresenta surpreendem e desafiam o Estado brasileiro a olhar para esse público com mais atenção e desenhar projetos que o incluam em pesquisas e CT. No assim chamado país do samba e do futebol, os jovens demonstraram mais interesse em pesquisas e CT do que nesses dois símbolos, ou mesmo dois estereótipos sobre as identidades da sociedade brasileira. Elegem medicina, questões ambientais e mudanças climáticas como temas de grande importância. Dos entrevistados, 67\% manifestaram interesse ou muito interesse pela CT. Sobre questões ambientais, o percentual sobe para $80 \%$, superando o interesse em religião, que fica em $67 \%$. Eles reconhecem a importância da educação pública e o papel de professores e cientistas de universidades e institutos de pesquisa - as pessoas em quem eles mais confiam. Ainda que com uma leitura um pouco confusa, os jovens brasileiros demonstram muito interesse em CT. Os que não acreditam em mudanças climáticas defendem a CT para o fortalecimento social. Os que são contra as vacinas reconhecem a necessidade de estudar e desenvolver recursos para combater os efeitos das mudanças climáticas. O livro mostra ainda que, entre os jovens brasileiros, o letramento em CT não altera o seu posicionamento em relação à ciência.

Quando procuram informações sobre CT, os jovens brasileiros priorizam programas e vídeos na TV, ferramentas online e conversas com amigos e familiares. Professores, contudo, são suas principais fontes. A internet continua sendo a principal fonte de buscas, com destaque para o Google, consultado por 79\% dos entrevistados. Os jovens brasileiros acreditam na CT como recurso indispensável para sustentabilidade socioambiental, inovação e saúde. Cientistas e professores são lembrados como suas fontes de informações mais confiáveis. Além disso, alguns dos jovens consultados consideram a carreira de cientista muito atraente, mas afirmam ser quase impossível ingressar nela. Para 93\% dos entrevistados, é muito difícil alcançar esse sonho. Defendem a necessidade de 
democratização do conhecimento e mais acesso da população aos recursos oferecidos pela CT. A imagem de cientista é colorida pelos jovens brasileiros com alguns estereótipos. Para 96\% dos entrevistados, cientistas são pessoas criativas que aprendem rápido. Contudo, 70\% acham que cientistas têm poucos amigos, $60 \%$ dizem que são esquisitos e $54 \%$ acreditam que, em geral, cientistas não são muito atraentes e não são felizes no casamento. Sobre a posição do Brasil no contexto global em CT, os jovens demonstram insatisfação, apontando atraso do país em relação ao que poderia produzir.

Em suas palavras de conclusão, o estudo aponta a forte manifestação dos jovens brasileiros em relação à importância da CT no dia a dia da sociedade. Esse entusiasmo, segundo os autores, deve ser aproveitado como estímulo para ações de problematização e sensibilização com os jovens, objetivando o seu engajamento em projetos de produção e difusão de conhecimentos.

O que os jovens brasileiros pensam sobre ciência e tecnologia? chega num momento oportuno para chamar nossa atenção sobre a necessidade urgente de escutar nossos jovens, que devem ser incluídos nas discussões sobre CT. A inclusão dessa parcela da população nessas ações, em todos os contextos nacionais, representará um passo importante para romper as barreiras entre as produções científicas e a sociedade. Rompimento esse fundamental para ampliar as percepções da juventude sobre as mudanças climáticas e seus impactos, além de outros desafios para os quais a ciência tem respostas. O livro aqui apresentado é uma contribuição indispensável para essa sensibilização. Ao evidenciar o interesse dos jovens brasileiros em CT, esse estudo torna-se fundamental para os desenhos de políticas públicas voltadas para a formatação de projetos educacionais que interessará ao ensino fundamental e à universidade, a associações científicas, profissionais em educação e pequisa, e à sociedade em geral.

\section{REFERÊNCIAS}

BASTIN, Jean-Francois et al. The global tree restoration potential. Science, v.365, p.76-79, 2019.

LEE, Katharine et al. Youth perceptions of climate change: a narrative synthesis. WIREs Climate Change, 22 fev. 2020. Disponível em: https://doi. org/10.1002/wcc.641. Acesso em: 9 jun. 2021.
MASSARANI, Luisa et al. O que os jovens brasileiros pensam da ciência e da tecnologia? Rio de Janeiro: Editora Fiocruz, 2021. Disponível em: https://www.inct-cpct.ufpa.br/wp-content/ uploads/2021/02/LIVRO_final_web_2pag.pdf. Acesso em: 9 jun. 2021. 